\title{
Impact of Brine Composition and Concentration on Capillary Pressure and Residual Oil Saturation in Limestone Core Samples
}

\author{
F. Feldmann ${ }^{1, *}, A . M$. AlSumaiti ${ }^{1,2}, S . K$. Masalmeh $^{2}, W . S$. AlAmeri $^{1}, S$. Oedai $^{1}$ \\ ${ }^{1}$ Department of Petroleum Engineering, Khalifa University of Science and Technology, SAN Campus, Abu Dhabi \\ ${ }^{2}$ Abu Dhabi National Oil Company (ADNOC)
}

\begin{abstract}
Low salinity water flooding (LSF) is a relatively simple and cheap EOR technique in which the salinity of the injected water is optimized (by desalination and/or modification) to improve oil recovery over conventional waterflooding. Extensive laboratory experiments investigating the effect of LSF are available in the literature. Sulfate-rich as well as diluted brines have shown promising potential to increase oil production in limestone core samples. To quantify the low salinity effect, spontaneous imbibition and/or tertiary waterflooding experiments have been reported. For the first time in literature, this paper presents a comprehensive study of the centrifuge technique to investigate low salinity effect in carbonate samples. The study is divided into three parts. At first, a comprehensive screening was performed on the impact of different connate water and imbibition brine compositions/combinations on the spontaneous imbibition behavior. Second, the subsequent forced imbibition of the samples using the centrifuge method to investigate the impact of brine compositions on residual saturations and capillary pressure. Finally, three unsteady-state (USS) core floodings were conducted in order to examine the potential of the different brines to increase oil recovery in secondary mode (brine injection at connate water saturation) and tertiary mode (exchange of injection brine at mature recovery stage). The experiments were performed using Indiana limestone outcrops. The main conclusions of the study are spontaneous imbibition experiments only showed oil recovery in case the salinity of the imbibing water (IW) is lower than the salinity of the connate water $(\mathrm{CW})$. No oil production was observed when the imbibing water had a higher salinity than the connate water or the salinity of the connate water and imbibing brine were identical. Moreover, the spontaneous imbibition experiments indicated that diluting the salinity of the imbibing water has a larger potential to spontaneously recover oil than the introduction of sulfate-rich sea water. The centrifuge experiments confirmed a connection between the overall salinity and oil recovery. As the salinity of the imbibing brines decreases, the capillary imbibition pressure curves showed an increasing water-wetting tendency and simultaneous reduction of the remaining oil saturation. The lowest remaining oil saturation was obtained for diluted sea water as CW and IW. The core flooding experiments reflected the results of the spontaneous imbibition and centrifuge experiments. Injecting brine at a rate of $0.05 \mathrm{cc} / \mathrm{min}$, sea water and especially diluted sea water resulted in a significant higher oil recovery compared to formation brine. Moreover, when comparing secondary mode experiments, the remaining oil saturation after flooding by diluted sea water, sea water and formation water was $30.6 \%, 35.5 \%$ and $37.4 \%$, respectively. In tertiary injection mode, sea water did not lead to extra oil recovery while diluted sea water led to an additional oil recovery of $5.6 \%$ in one out of two tertiary injection applications.
\end{abstract}

\section{Introduction}

The concept of low salinity injection into a sandstone has been extensively investigated at laboratory and field scale since the early 90s. Although the mechanism behind low salinity is still not well understood, it is widely accepted that low salinity injection has positive impact on oil production [1]. The research group of Austad et al. [2] [3] conducted comprehensive low salinity studies on Stevns Klint (chalk) outcrops, demonstrating that besides the total salinity, multivalent ions such as magnesium, calcium and sulfate affected the sample wettability and oil recovery. Although chalk and limestone are both composed of

*corresponding author: ffeldmann@pi.ac.ae

(c) The Authors, published by EDP Sciences. This is an open access article distributed under the terms of the Creative Commons Attribution License 4.0 (http://creativecommons.org/licenses/by/4.0/). 
calcium carbonate, chalk has a finer texture and is furthermore purely biogenic. As the pore surface of chalk is typically much larger compared to limestone, the reactivity of chalk towards ions is supposed to be higher. Therefore, it is questionable if the suggested explanations of low salinity effects in chalks can also be applied on limestones samples [3]. The research on low salinity currently focuses on two approaches to increase oil production in limestones. First, it is believed, that the concentration increase of multivalent anions can lead to the replacement of the acid oil components from the positively charged limestone surface. Secondly, it has been shown, that the significant reduction of the total ionic strength can improve oil production by the injection of very low salinity brines [4]. The potential of sulfate ions to increase oil production in two Middle East limestone reservoir cores has been demonstrated by Strand et al. [3]. The spontaneous oil recovery due to imbibition of synthetic sea water was approximately $15 \%$ higher compared to the sulfate-free reference sea water. Lighthelm et al. [5] observed an oil recovery increase of approximately $5 \%$, when the brine used in a spontaneous imbibition experiment on a Middle East limestone was sulfate-enriched. While the above mentioned studies focused on the impact of sulfate on spontaneous imbibition behavior, Nasaralla et al. [6] and Ramanuka et al. [4] additionally investigated the impact of the total ionic strength on oil recovery. On one hand, the work of Nasaralla et al. confirms the potential of sulfate-rich sea water to spontaneously displace oil from limestone cores, on other hand, it was simultaneously demonstrated that the injection of 10-times diluted sea water led to a $15 \%$ higher oil recovery compared to sea water. These results are in accordance to the study of Ramanuka et al., which includes samples from three different Middle East limestone reservoirs. Both, sea water as well as diluted sea water reveal promising potential to increase oil recovery during spontaneous imbibition. The overall highest oil recovery of $19.3 \%$ and $18.5 \%$ was however observed when the imbibing brine contained less than $1 \mathrm{~g} / \mathrm{l}$ of sodium chloride and insignificant sulfate concentration. Although spontaneous imbibition tests are helpful to screen the applicability and benefits of possible injection fluids, they do not necessarily reveal evidence about improved oil recovery [7]. Therefore, the impact on the residual oil saturation has to be studied with the help of displacement experiments such as core floodings or centrifuge experiments. Compared to the injection of formation brine, the limestone reservoir core floodings in the work of Nasaralla et al. [6] led to an additional oil recovery of $6 \%-7 \%$ using diluted sea water in secondary injection mode. However, a reduction of the remaining oil saturation in tertiary injection mode was not observed. After changing the injection brine from formation brine to sea water, Gupta et al. [8] reported an incremental oil recovery of $5.1 \%$ from a limestone reservoir sample. Additionally, the tertiary injection of sulfate-free sea water into a reference sample led to an incremental oil recovery of $9 \%$. Yousef et al. [9] demonstrated the potential of diluted sea water to enhance oil recovery in carbonates at reservoir conditions. After the injection of sea water in secondary mode, the two core floodings resulted into an additional oil recovery of $7 \%$ and $8.5 \%$, respectively for two-times diluted sea water and $9 \%$ and $10 \%$, respectively for ten-times diluted sea water.

\section{Preparation}

\subsection{Core preparation}

The experiments were conducted on Indiana limestone outcrop samples. The 1.5 -inch thick cores were initially CT-scanned, trimmed and smoothed down to 2-inch lengths (cf. Table 1). Subsequently, the cores were flushed by roughly 10 pore volumes of methanol until the produced fluid became colorless. After drying the core under vacuum, nitrogen permeability was measured to ensure an equal distribution of the different brine configuration on lower and higher permeable cores. The samples were vacuum saturated with formation brine and subsequently pressurised for 48 hours at 2000 psi. Porosity was calculated based on the weight difference between saturated and dried cores. The absolute brine permeability was measured at a confining pressure of 500 psi and back pressure of 100 psi. Nuclear magnetic resonance (NMR) tests of the $100 \%$ brine saturated samples reveal dual porosity properties.

\subsection{Fluid preparation}

Three different brine compositions are used in the experiments. A high-saline formation brine (total dissolved solids (TDS) of $\sim 183 \mathrm{kppm}$ ), sea water (TDS $\sim 44 \mathrm{kppm}$ ) and 100-times diluted sea water (TDS $\sim 0.4 \mathrm{kppm}$ ). All brines were synthesized based on a provided composition analysis and filtered prior to be using (cf. Error! Reference source not found.). Brine density and viscosity were determined as a function of temperature. At ambient conditions, the used dead crude oil is characterized by a density of $0.83 \mathrm{~g} / \mathrm{cm}^{3}$ and a viscosity of $4.19 \mathrm{cP}$. In order to remove debris and heavy fluid components, the oil was centrifuged for $30 \mathrm{~min}$ at a rotation speed of 5000 RPM.

\subsection{Primary brine drainage}

Two fully automated Beckmann ultra-centrifuges were utilized in this study. The initial water saturation $\left(\mathrm{S}_{\mathrm{wi}}\right)$ was established in a drainage centrifuge experiment by applying 12000 RPM for at least 48 hours. The obtained initial water saturation ranged between $23.0 \%-32.5 \%$. For the validation of the connate water saturations, a NMR 
based differentiation between the free fluid bulk volume (FFV) and the bulk volume of irreducible water volume (BVI) was calculated as proposed by Coates et al. [10]. Thereby, the obtained T2-relaxation times are divided into free and bound water based on core material dependent cut-off time. Integrating the area under T2-relaxation and applying a cut-off time of $98 \mathrm{~ms}$ as suggested by Chang et al. [11], the obtained values are in agreement with the obtained values of the drainage experiments (cf. Table 1).

Table 1: Core properties of the spontaneous imbibition and forced centrifuge imbibition section.

\begin{tabular}{|c|c|c|c|c|c|c|c|c|c|c|c|}
\hline $\begin{array}{c}\text { Grou } \\
\text { p }\end{array}$ & Sample & $\mathrm{CW}$ & IW & $\begin{array}{c}\text { Porosit } \\
\mathbf{y} \\
{[\%]}\end{array}$ & $\begin{array}{l}\text { Brine } \\
\text { perm. } \\
{[\mathrm{md}]}\end{array}$ & $\begin{array}{c}\text { Eff. oil } \\
\text { perm. } \\
\text { before } \\
\text { aging } \\
\text { [md] }\end{array}$ & $\begin{array}{l}\text { Eff. oil } \\
\text { perm. after } \\
\text { aging } \\
\text { [md] }\end{array}$ & $\begin{array}{l}\text { NMR } \\
\text { cut-off } \\
{[\%]}\end{array}$ & $\begin{array}{l}\text { Swi } \\
{[\%]}\end{array}$ & $\begin{array}{c}\text { Sw after spon. } \\
\text { imb. } \\
{[\%]}\end{array}$ & $\begin{array}{c}\text { Sw average after } \\
\text { forced imb. } \\
{[\%]}\end{array}$ \\
\hline \multirow{6}{*}{ I } & In 3 & FB & FB & 15.0 & 8.6 & 9.1 & 7.3 & 28.2 & 27.0 & 28.4 & 80.5 \\
\hline & In5 & FB & FB & 15.3 & 10.7 & 12.6 & 7.9 & 28.2 & 24.5 & 25.2 & 82.6 \\
\hline & $\operatorname{In} 7$ & SW & SW & 14.3 & 4.0 & 3.4 & 2.6 & 34.9 & 32.4 & 34.0 & 89.1 \\
\hline & In12 & SW & SW & 15.2 & 7.9 & 7.1 & 4.9 & 28.8 & 32.9 & 34.3 & 90.6 \\
\hline & In 4 & $\begin{array}{l}\text { DS } \\
\mathbf{W}\end{array}$ & DSW & 14.9 & 6.9 & 5.5 & 3.8 & 28.5 & 31.2 & 33.3 & 92.5 \\
\hline & In13 & $\begin{array}{l}\text { DS } \\
\mathbf{W} \\
\end{array}$ & DSW & 15.4 & 14.5 & 9.9 & 7.0 & 27.8 & 29.8 & 31.8 & 92.3 \\
\hline \multirow{4}{*}{ II } & In 2 & FB & SW & 15.6 & 15.0 & 12.8 & 11.1 & 26.2 & 26.4 & 45.1 & 88.3 \\
\hline & $\operatorname{In} 10$ & FB & SW & 14.9 & 6.2 & 5.6 & 2.5 & 26.7 & 30.4 & 43.4 & 85.0 \\
\hline & In1 & FB & DSW & 15.6 & 8.5 & 9.4 & 7.1 & 28.4 & 30.2 & 55.4 & 91.9 \\
\hline & In9 & FB & DSW & 15.3 & 11.7 & 11.5 & 8.1 & 23.0 & 25.7 & 51.5 & 90.2 \\
\hline \multirow{2}{*}{ III } & In16 & SW & DSW & 14.4 & 4.8 & 6.4 & 5.6 & 32.5 & 28.6 & 44.6 & 85.2 \\
\hline & In17 & SW & DSW & 14.9 & 14.5 & 11.2 & 10.2 & 29.9 & 25.8 & 42.4 & 87.4 \\
\hline \multirow{2}{*}{ IV } & In14 & $\begin{array}{l}\text { DS } \\
\text { W }\end{array}$ & FB & 15.3 & 11.8 & 11.2 & 8.9 & 26.8 & 24.0 & 24.0 & 80.2 \\
\hline & $\operatorname{In} 15$ & $\begin{array}{l}\text { DS } \\
\text { W }\end{array}$ & SW & 14.9 & 5.1 & 5.5 & 4.9 & 29.0 & 26.3 & 26.3 & 85.7 \\
\hline
\end{tabular}

Table 2: Core properties of the core flooding section.

\begin{tabular}{|c|c|c|c|c|c|c|c|c|c|c|}
\hline Sample & $\mathrm{CW}$ & $\begin{array}{c}\text { Secondary } \\
\text { injection } \\
\text { brine }\end{array}$ & $\begin{array}{l}\text { Tertiary } \\
\text { injection } \\
\text { brine (a) }\end{array}$ & $\begin{array}{l}\text { Tertiary } \\
\text { injection } \\
\text { brine (b) }\end{array}$ & $\begin{array}{c}\text { Porosity } \\
{[\%]}\end{array}$ & $\begin{array}{l}\text { Brine perm. } \\
{[\text { [md] }}\end{array}$ & $\begin{array}{l}\text { Swi } \\
{[\%]}\end{array}$ & $\begin{array}{c}\text { Sw after } \\
\text { secondary } \\
\text { Inj. } \\
{[\%]}\end{array}$ & $\begin{array}{c}\text { Sw after } \\
\text { tertiary Inj. } \\
\text { (a) } \\
{[\%]}\end{array}$ & $\begin{array}{c}\text { Sw after } \\
\text { tertiary } \\
\text { Inj. (b) } \\
{[\%]}\end{array}$ \\
\hline In $2 b$ & FB & FB & SW & DSW & 15.4 & 14.8 & 21.8 & 62.6 & 62.6 & 62.6 \\
\hline In $4 b$ & FB & SW & DSW & -- & 14.5 & 7.4 & 26.5 & 64.5 & 68.3 & -- \\
\hline In9b & FB & DSW & -- & -- & 15.2 & 12.3 & 24.9 & 69.4 & -- & -- \\
\hline
\end{tabular}

Table 3: Brine compositions.

\begin{tabular}{|c|c|c|c|c|c|c|c|c|c|c|}
\hline Brine & $\begin{array}{c}\text { Sodium } \\
\text { [mol] }\end{array}$ & $\begin{array}{c}\text { Potassium } \\
\text { [mol] }\end{array}$ & $\begin{array}{c}\text { Calcium } \\
\text { [mol] }\end{array}$ & $\begin{array}{l}\text { Magnesium } \\
\text { [mol] }\end{array}$ & $\begin{array}{l}\text { Strontium } \\
\text { [mol] }\end{array}$ & $\begin{array}{l}\text { Chlorine } \\
\text { [mol] }\end{array}$ & $\begin{array}{c}\text { Bromine } \\
\text { [mol] }\end{array}$ & $\begin{array}{c}\text { Sulfate } \\
\text { [mol] }\end{array}$ & $\begin{array}{l}\text { TDS } \\
(\mathrm{g} / \mathrm{l})\end{array}$ & $\begin{array}{c}\text { Ionic } \\
\text { strength }\end{array}$ \\
\hline $\begin{array}{c}\text { Formation } \\
\text { brine }\end{array}$ & 2.237 & 0.023 & 0.372 & 0.084 & 0.009 & 3.165 & 0.009 & 0.004 & 183.4 & 3.655 \\
\hline Sea water & 0.587 & 0.013 & 0.013 & 0.065 & 0.0001 & 0.680 & 0 & 0.037 & 43.8 & 0.870 \\
\hline $\begin{array}{l}\text { 100-times } \\
\text { diluted Sea }\end{array}$ & 0.00587 & 0.00013 & 0.00013 & 0.00065 & 0.000001 & 0.00680 & 0 & 0.00037 & 0.438 & 0.0087 \\
\hline
\end{tabular}

\subsection{Core aging}

The core plugs were placed inside a steel accumulator at $\mathrm{S}_{\mathrm{wi}}$, separated by small plastic meshes and surrounded by crude oil. The accumulator was then placed inside an oven at $90^{\circ} \mathrm{C}$ and connected to a pump to ensure a constant crude oil pressure of 100 psi. The core samples were aged for 30 days while the aging process was monitored by the determination of the effective oil permeability before and 
after aging. Under a confining pressure of $500 \mathrm{psi}$ and a backpressure of $100 \mathrm{psi}$, the effective oil permeability was measured at a temperature of $45^{\circ} \mathrm{C}$ to avoid phase plugging due to wax in the crude oil. All samples exhibited a permeability reduction in the range of $10 \%-40 \%$, which indicates a wettability modification towards more oil-wetting properties (cf. Table 1). The oil permeability measurements did not lead into further water displacement. A change in the absolute permeability before and after the experimental study was now observed.
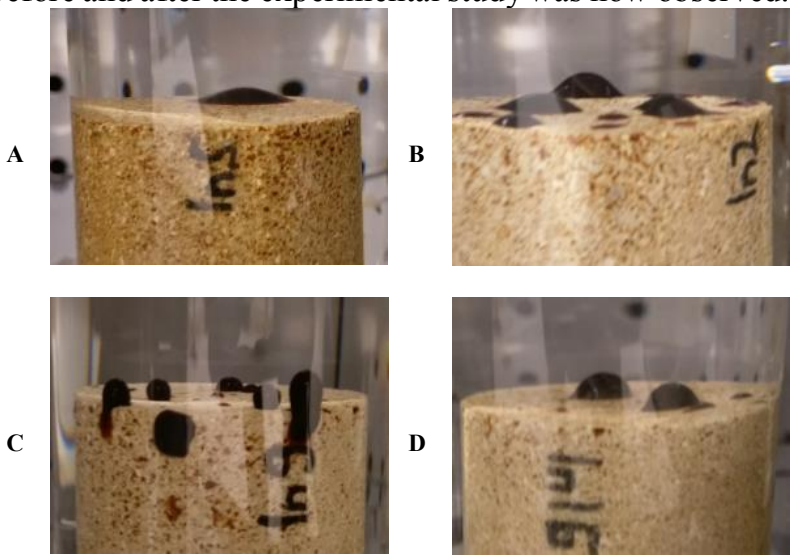

Figure 1: Spontaneous brine imbibition at $70^{\circ} \mathrm{C}$. A: Formation brine (CW) - Formation brine (IW), B: Formation brine (CW) Sea water (IW), C: Formation brine (CW) - Diluted sea water (IW), D: Sea water (CW) - Diluted sea water (IW).

\section{Spontaneous imbibition}

After aging, the cores were placed inside Amott cells, surrounded by the selected imbibing brine and heated up to $70^{\circ} \mathrm{C}$ at ambient pressure. The temperature increase at the beginning of the experiments requires the correction of the oil production data, as the first oil recovery will be mainly caused by thermal expansion. In order to gain an improved understanding regarding the requirements of low salinity effects in limestones, the systematic experimental study emphasizes the impact of both, connate as well as imbibing brine composition. A highsalinity formation brine, sulfate-rich sea water and (100times) diluted sea water are used in the study (cf. Error! Reference source not found.). For reproducibility, each selected brine configuration was tested on two core samples. Preferably one higher permeable and one less permeable limestone sample. The performed experiments are classified into four groups.

\subsection{Group I: Identical salinity of connate water and imbibing water}

Group I examines the spontaneous imbibition behavior in case the connate and imbibition brine are identical. Using formation brine as connate water (CW) and imbibing water (IW), a marginal oil recovery of $1.9 \%$ and $1.0 \%$, respectively was observed (cf. Table 1, Figure 2). The negligible small oil production indicates oil wetting properties as the brine is prohibited to migrate into the cores. The spontaneous oil production of sea water as $\mathrm{CW}$ and IW resulted into $2.5 \%$ and $2.1 \%$ recovery respectively, which is indicative of similar wetting conditions. Finally, diluted sea water as CW and IW caused minor oil recovery of $3.1 \%$ and $2.7 \%$ respectively. Figure 2 illustrates, that, independently of the brine composition and salinity, no oil recovery was observed as long as the salinity of the connate and imbibing water was identical.

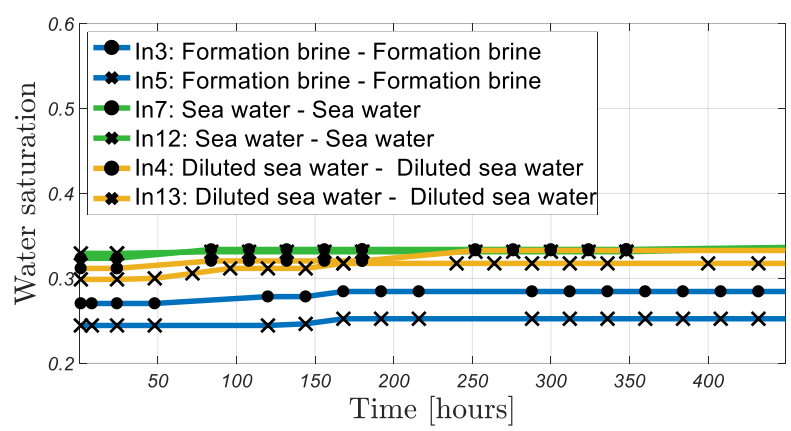

Figure 2: Spontaneous imbibition group I.

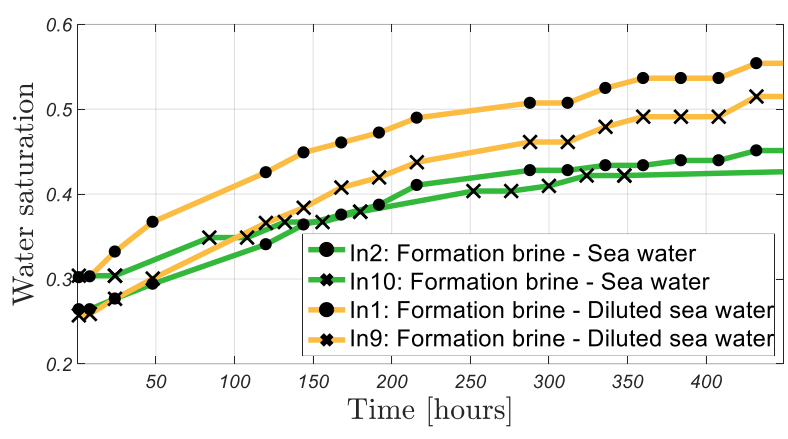

Figure 3: Spontaneous imbibition group II.

\subsection{Group II/Group III: Injection of lower salinity brine into a system at higher salinity:}

Based on a common low-salinity definition, the samples of test group II (formation brine as CW) and group III (sea water as $\mathrm{CW}$ ) consist of a high-salinity connate water and lower salinity imbibition brine. An oil recovery of $25.4 \%$ and $18.7 \%$ was observed when using formation brine as $\mathrm{CW}$ and sea water as IW (cf. Figure 3). Compared to formation brine, the synthetic sea water is approximately 4-times less saline, but has a significant sulfate concentration of $37 \mathrm{mMol} / \mathrm{l}$. Therefore, the obtained production might be caused by the introduction of sulfate ions into the brine-oil-solid system and/or the reduction of the total salinity. The overall highest spontaneous oil recovery of $36.1 \%$ and $34.7 \%$ was observed for formation brine as $\mathrm{CW}$ and the 400-times less saline diluted sea water (sulfate concentration of $0.037 \mathrm{mMol} / \mathrm{l}$ ) 
as IW. In this case, the spontaneous oil recovery is likely to be driven by the large salinity difference between the connate and imbibition brine. To further investigate the promising potential of diluted sea water to spontaneously produce oil, the core samples of group III contain sea water as $\mathrm{CW}$ and the 100-times less saline diluted sea water as IW. The spontaneous imbibition resulted in an oil recovery of $22.5 \%$ and $22.3 \%$ (cf. Figure 4 ) which is in average $13 \%$ less oil recovery compared to formation

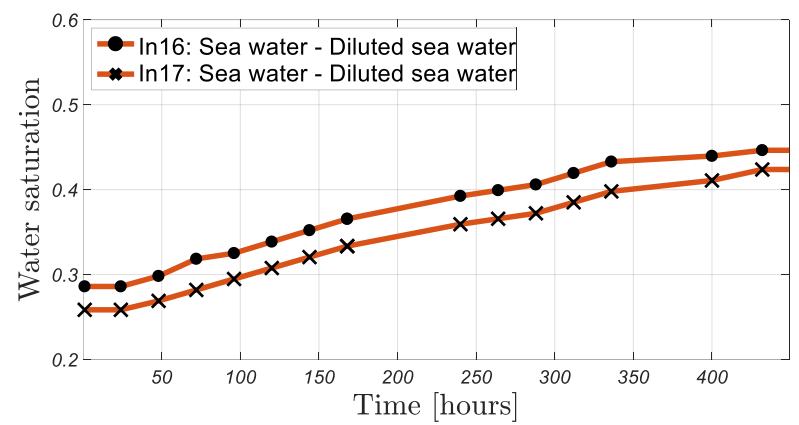

Figure 4: Spontaneous imbibition group III.

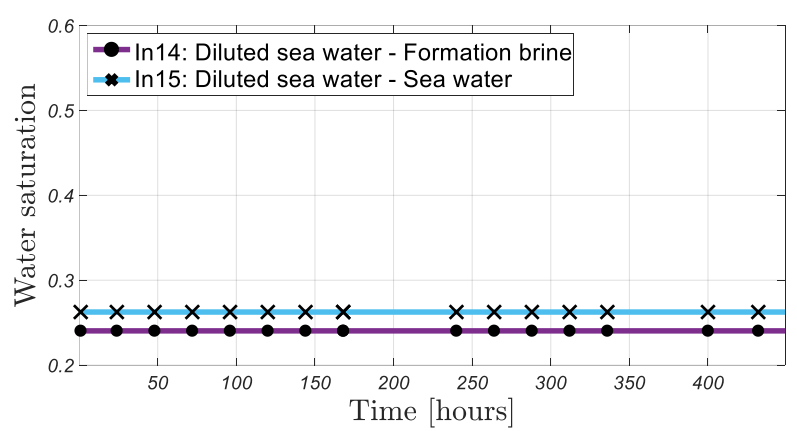

Figure 5: Spontaneous imbibition group IV.

brine as CW and diluted sea water as IW. The results are indicating, that the establishment of a large salinity difference between connate and imbibing water is leading to higher oil recovery rather than introduction/presence of sulphate ions into the system.

\subsection{Group IV: Injection of higher salinity brine into system at lower salinity}

To complete the possible CW and IW combinations, Group IV reverses the conventional low-sanity tests: Two cores were initially saturated in diluted sea water and then imbibed by formation brine and sea water. None of the cores showed oil production as illustrated in Figure 5.

\section{Forced imbibition}

In this paper we report for the first time, as far as we know, the use of centrifuge experiments to investigate the impact of brine composition and concentration on imbibition capillary pressure curve and remaining oil saturation. The imbibition capillary pressure curves of the experiments are illustrated in Figure 6 to Figure 9, where the experimentally acquired data were initially smoothed by applying the least-squares solutions of a three-constant hyperbolic as proposed by Donaldson et al. [12]. To correct the experimentally obtained average water saturation in respect to the inlet water saturation, the Forbes First Solution was applied [13].

\subsection{Centrifuge preparation}

The sample holders of the used Beckmann Ultracentrifuge consist of two parts: A steel core holder to place the core samples and a light transparent receiving tube which ensures the continuous imaging of the fluid level. After placing the cores inside the bucket and pouring the imbibition brine, a known amount of oil was added to enable a sharp interface between the brine and oil at the start of the experiment. The centrifuge buckets and rotor were then preheated inside an external oven to $70^{\circ} \mathrm{C}$, mounted and placed inside the centrifuge. In the range of 1000 to $7500 \mathrm{RPM}$, nine rotation speeds were selected to ensure a proper measurement of imbibition capillary pressure curves as well as to reach remaining oil saturation. Each imbibition step was run for at least 30 hours until gravity forces and capillary force were in equilibrium and thus a stable production plateau was reached. After completing the centrifuge runs, the recorded pixels were converted into fluid production in respect to the physically captured oil. The obtained average remaining oil saturations range between $7.5 \%-19.8 \%$ which is characteristic for mixed to oil-wet carbonates as reported for example by Masalmeh [14]. However, the application of the Forbes First Solution resulted into remaining oil inlet saturations between $3 \%-16.8 \%$. Especially for the low salinity brine configurations, Table 1 shows a larger discrepancy between average and inlet saturations likely caused by the overestimation of the inlet saturations.

\subsubsection{Group I}

Identical salinity of connate water and imbibing water: During the spontaneous imbibition tests, all the experiments which were performed using the same CW and IW showed non-water-wet behavior as the oil production ranged between $1.0-3.1 \%$ of the OIIP. The imbibition capillary pressure curves for the same samples demonstrate a connection between decreasing brine salinity and decreasing oil wetting tendency, i.e., the capillary pressure is less negative for the samples of lower salinity, as shown in Figure 6. In accordance, the endpoint of the capillary pressure curves demonstrates the effect of brine composition on the remaining oil saturation: Formation brine as $\mathrm{CW}$ and IW resulted in a remaining oil saturation (ROS) of $16.8 \%$ and $14.2 \%$, sea water as CW and IW resulted in a ROS of $8.4 \%$ and $7.4 \%$ and diluted 
sea water as CW and IW resulted into a ROS of $3.0 \%$ and $4.1 \%$, respectively.

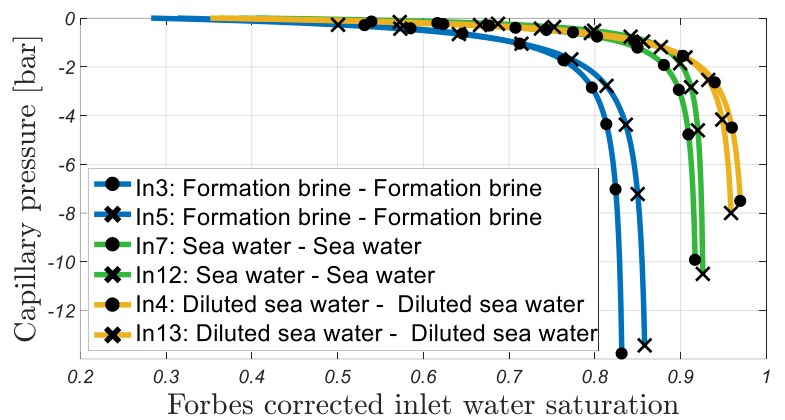

Figure 6: Forced imbibition group I.

\subsubsection{Group II/Group III}

Injection of lower salinity brine into system at higher salinity: Due to the previous high spontaneous brine imbibition, the forced imbibition of formation brine as $\mathrm{CW}$ and sea water or diluted sea water as IW started at much higher water saturations around $42 \%$ to $55 \%$, respectively. Compared to the imbibition of the high saline formation brine, both lower saline combinations show a weaker oil wetting imbibition capillary pressure curves (i.e., less negative) as well as a lower remaining oil saturations (cf. Figure 7). Formation brine as $\mathrm{CW}$ and sea water as IW resulted in a ROS of $9.1 \%$ and $13.2 \%$, respectively while formation brine $(\mathrm{CW})$ and diluted sea water (IW) resulted in a ROS of $4.9 \%$ and $6.5 \%$, respectively. The results of the forced imbibition of sea water (CW) by diluted sea water (IW) are displayed in Figure 8. In accordance to the spontaneous imbibition tests, the obtained remaining oil saturations of $12.0 \%$ and $10.0 \%$ are in the range of formation brine $(\mathrm{CW})$ and sea water (IW). The experiments are indicating that, under the presence of a high salinity connate water, the most efficient oil recovery is observed as the salinity difference between connate water and imbibition brine is maximized.

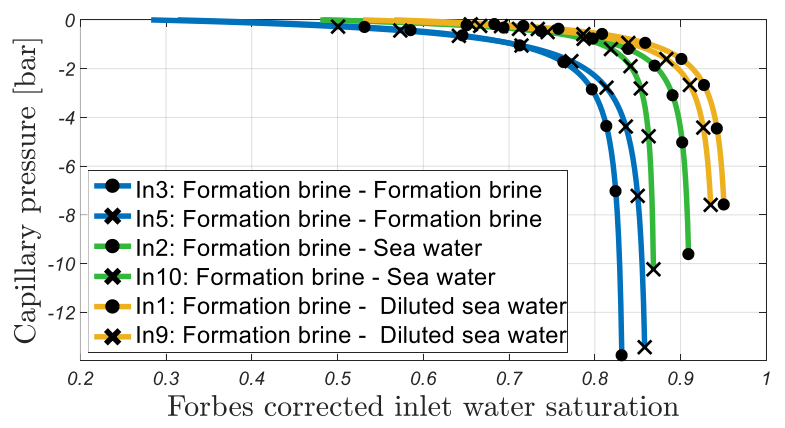

Figure 7: Forced imbibition group II plus In3 and In5.

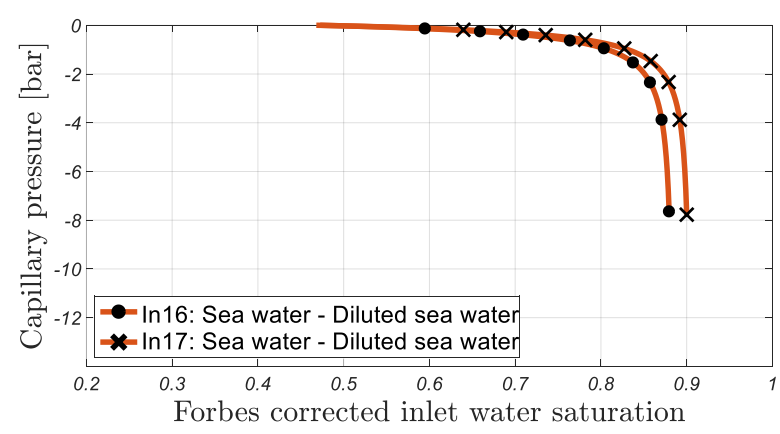

Figure 8: Forced imbibition group III.

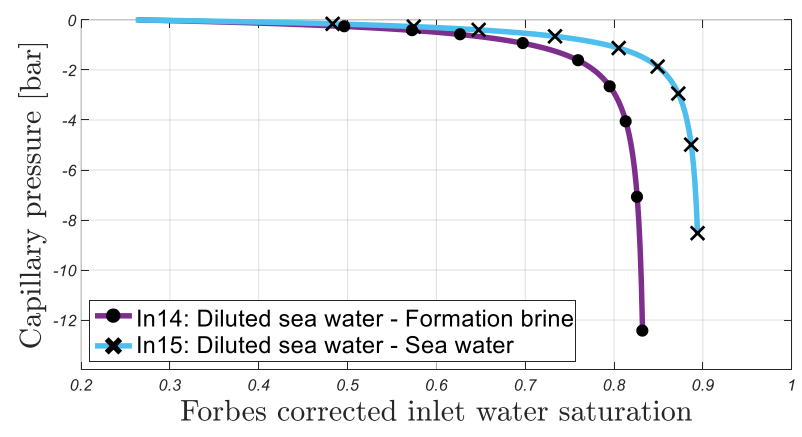

Figure 9: Forced imbibition group IV.

\section{Core flooding}

The spontaneous imbibition and centrifuge experiments showed promising potential of the sea water and especially of the diluted sea water to increase oil production. For the completeness of the study, three unsteady state displacement experiments were conducted. Injection of formation brine in secondary mode followed by sea water and desalinated sea water in tertiary mode (1), injection of sea water in secondary mode followed by desalinated sea water in tertiary mode (2), and finally, the injection of desalinated sea water in secondary mode (3). Where the secondary injection mode represents the injection of brine at connate water saturation and the tertiary injection mode expresses the exchange of the injection brine at mature recovery stage. All core floodings used formation brine as CW. A Vinci Auto flood 700 was used for the experiments. In line with the spontaneous and forced imbibition tests, the experiments were conducted at $70^{\circ} \mathrm{C}$. After completing the centrifuge experiments, the outcrop samples were re-cleaned by an alternating injection of toluene and methanol. The samples were saturated, drained in the centrifuge to reach initial water saturation and finally aged as described earlier (cf. Error! Reference source not found.). To ensure the continuous and precise production monitoring, an automatized fraction collector unit was connected at the downstream of the core flooding device. Confining pressure was set to $1500 \mathrm{psi}$, while a 
back pressure of $200 \mathrm{psi}$ was selected. The injection rates used in the experiments are $0.05,0.2,1,3$ and $5 \mathrm{cc} / \mathrm{min}$, respectively. Thereby, the first injection rate of $0.05 \mathrm{cc} / \mathrm{min}$ represents field rate equivalent of approximately 1 foot/day. However, in this case and due to the non-water-wet behavior of the core samples, strong capillary end effect is expected which will affect the oil recovery. The subsequent higher flowrates are used in order to overcome the capillary end effect and thus reach remaining oil saturation. The obtained saturations were validated by applying Dean-Stark extraction.

\subsection{Formation brine in secondary mode}

The pressure and water saturation evolution for the injection of formation brine in secondary injection mode followed by sea water and diluted sea water is illustrated in Figure 10. Injecting formation brine at field rate, $21.9 \%$ of the OIIP is recovered while the majority of the oil remains immobile possibly due to heterogeneity, unstable displacement, capillary end effect and capillary trapping. The stepwise increase of the injection rate resulted in a remaining oil saturation of $37.4 \%$. The subsequent injection of sea water and diluted sea water in tertiary mode did not improve the oil recovery, although Figure 10 shows a decrease of the differential pressure. At $70^{\circ} \mathrm{C}$, the viscosity of sea water amounts $74 \%$ of the viscosity of formation brine and the viscosity of diluted sea water amounts $67 \%$ of the viscosity of the formation brine.

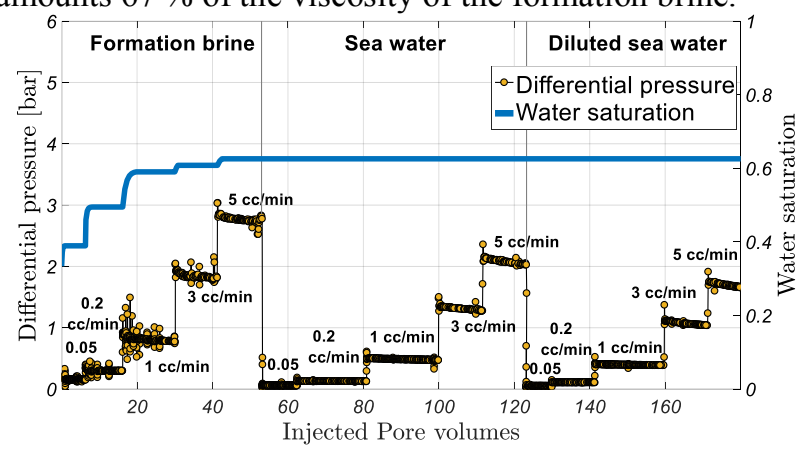

Figure 10: Injection of formation brine in secondary mode followed by the injection of sea water and diluted sea water (In2b).

\subsection{Sea water in secondary mode}

The second core flooding started with the injection of sea water in secondary mode followed by the injection of diluted sea water in tertiary mode (Figure 11). At the first injection rate of $0.05 \mathrm{cc} / \mathrm{min}, 30.1 \%$ of the oil is recovered. After bumping up the injection rates, a remaining oil saturation of $35.5 \%$ was obtained. The following injection of diluted sea water led to an additional oil recovery of $3.4 \%$ at an injection rate of $1 \mathrm{cc} / \mathrm{min}$, followed by additional $1.8 \%$ oil recovery at an injection of $3 \mathrm{cc} / \mathrm{min}$ and $5 \mathrm{cc} / \mathrm{min}$. The oil saturation at the end of the experiment was $31.7 \%$.

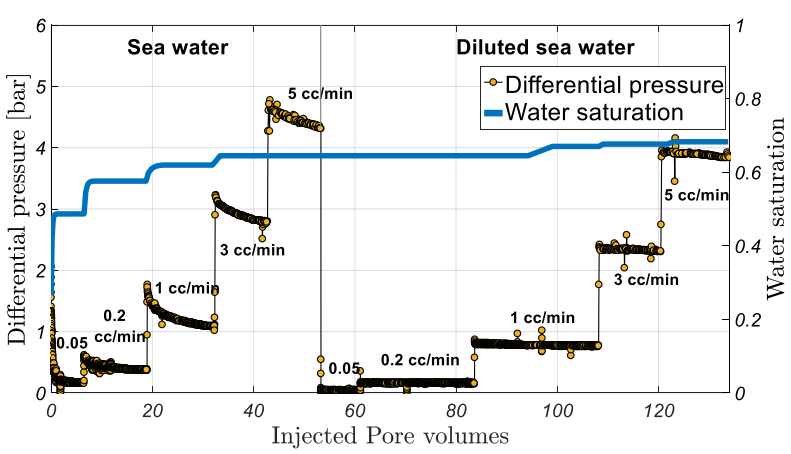

Figure 11: Injection of sea water in secondary mode followed by the injection diluted sea water $(\operatorname{In} 4 b)$.

\subsection{Diluted Sea water in secondary mode}

Figure 12 shows an oil recovery of $38.5 \%$ for the injection of diluted sea water at field rate. In accordance to the capillary pressure curves imbibition curve, the USS flooding experiments showed significant higher oil production at the same low injection rate $(0.05 \mathrm{cc} / \mathrm{min})$ compared to formation brine. The core flooding resulted into a remaining oil saturation of $30.6 \%$. The flooding experiments show much higher oil saturation compared to the centrifuge experiments. This is mainly due to the adverse mobility ratio and the heterogeneity of the samples which have dominant effects on USS experiments while they have hardly any effect on the centrifuge experiments results. Although the USS results are still in line with the centrifuge data and show that oil recovery is correlated with low salinity, a sequence of ISSM core floodings is planned to gain an improved understating of the displacement process.

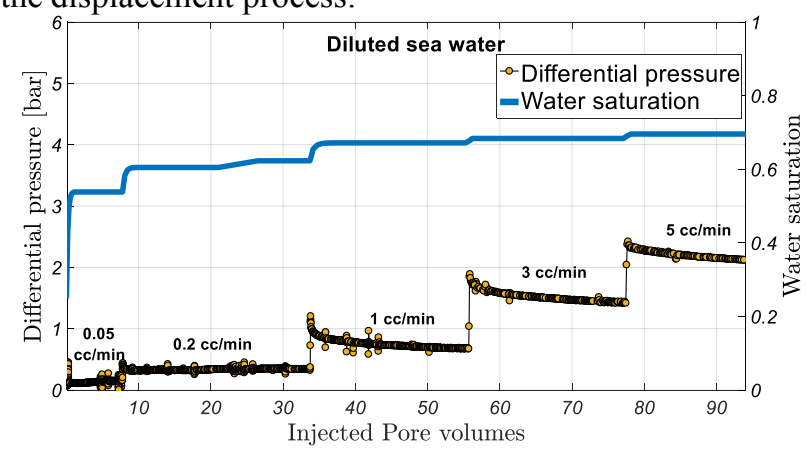

Figure 12: Injection of diluted sea water in secondary mode (In9b).

\section{Conclusions}

A comprehensive low-salinity study on limestone outcrop samples has been reported. The study combines 
spontaneous imbibition experiments, centrifuge method and unsteady state core floodings. The main conclusions of the study are:

- Spontaneous imbibition experiments resulted in oil recovery in case the imbibing water had a lower salinity than the connate water. No oil production was observed in case the imbibing water had a higher or the same salinity as the connate water.

- Formation brine as CW and diluted sea water as IW led to an approximately $13.4 \%$ higher spontaneous imbibition compared to formation brine as $\mathrm{CW}$ and sea water as IW. Diluted sea water (IW) spontaneously recovered roughly $22.4 \%$ oil from initially sea water saturated cores.

- The imbibition capillary pressure curves are characterized by increasing water-wetting tendency and a simultaneous reduction of the remaining oil saturation, as the salinity of the imbibition brines decreases in comparison to formation brine.

- Forced imbibition centrifuge experiments demonstrated the impact of the brine composition and concentration on oil recovery. Using formation brine as CW, diluted sea water (IW), sea water (IW) and formation brine (IW) led into a final average remaining oil saturation of $9.0 \%, 13.1 \%$ and $18.5 \%$, respectively. The highest oil recovery was observed when diluted sea water was used as CW and IW.

- Applying an injection rate of $0.05 \mathrm{cc} / \mathrm{min}$ in secondary injection mode, formation brine led to $21.9 \%$ recovery, sea water to $30.1 \%$ recovery and diluted sea water to $38.5 \%$ oil recovery. While this is not representative of reservoir conditions due to capillary end effect, however, this demonstrates the impact of injection water on wettability and potentially relative permeability.

- When comparing the secondary mode experiments, the final remaining oil saturation for diluted sea water injection, sea water injection and formation water injection was $30.6 \%, \quad 35.5 \%$ and $37.4 \%$, respectively.

We would like to acknowledge ADNOC for their financial support and for providing the facilities of the ADNOC Research and Innovation Center for this study.

\section{References}

[1] Sheng, J. J., "Critical review of low-salinity waterflooding," Journal of Petroleum Science and Engineering, (2014), 120, 216-224.

[2] Zhang, P., Tweheyo, M. T., \& Austad,T., "Wettability alteration and improved oil recovery by spontaneous imbibition of seawater into chalk: Impact of the potential determining ions $\mathrm{Ca} 2+, \mathrm{Mg} 2+$ and SO42-," Colloids and
Surfaces A: Physicochemical and Engineering Aspects, (2007), 301 (1-3), 199-208.

[3] Strand, S., Austad, T., Puntervold, T., Høgnesen, E. J., Olsen, M., \& Barstad, S. M. F., "“'Smart water" for oil recovery from fractured limestone: a preliminary study," Energy \& fuels, (2008), 22 (5), 3126-3133.

[4] Romanuka, J., Hofman, J., Ligthelm, D.J., Suijkerbuijk, B., Marcelis, F., Oedai, S., Brussee, N., van der Linde, H., Aksulu, H. and Austad, T., "Low salinity EOR in carbonates", SPE 153869, SPE Improved Oil Recovery Symposium, Oklahoma, USA, (2012), April 1418.

[5] Ligthelm, D. J., Gronsveld, J., Hofman, J., Brussee, N., Marcelis, F., \& van der Linde, H., "Novel Waterflooding Strategy By Manipulation Of Injection Brine Composition", SPE 119835, EUROPEC/EAGE Conference and Exhibition, Amsterdam, The Netherlands, (2009), June 8-11.

[6] Nasralla, R.A., Mahani, H., van der Linde, H.A., Marcelis, F.H., Masalmeh, S.K., Sergienko, E., Brussee, N.J., Pieterse, S.G. and Basu, S., "Low Salinity Waterflooding for a carbonate reservoir: Experimental evaluation and numerical interpretation," Journal of Petroleum Science and Engineering, (2018).

[7] Masalmeh, S. K., Sorop, T. G., Suijkerbuijk, B. M., Vermolen, E. C., Douma, S., Van Del Linde, H. A., \& Pieterse, S. G. J., "Low salinity flooding: Experimental evaluation and numerical interpretation", IPTC 17558, International Petroleum Technology Conference, Doha, Qatar, (2014), January 19-22.

[8] Gupta, R., Smith, G. G., Hu, L., Willingham, T., Lo Cascio, M., Shyeh, J. J., \& Harris, C. R., "Enhanced waterflood for carbonate reservoirsimpact of injection water composition", SPE 142668, SPE Middle East Oil and Gas Show and Conference, Manama, Bahrain, (2011), September 25-28.

[9] Yousef, A. A., Al-Saleh, S., Al-Kaabi, A. U., \& Al-Jawfi, M. S., "Laboratory investigation of novel oil recovery method for carbonate reservoirs", SPE 137634, Canadian Unconventional Resources and International Petroleum Conference, Calgary, Canada, (2010), October, 19-21.

[10] Coates, G. R., Galford, J., Mardon, D., \& Marschall, D., "A new characterization of bulkvolume irreducible using magnetic resonance," The Log Analyst, (1998), 39 (01).

[11] Chang, D., Vinegar, H. J., Morriss, C., \& Straley, C, "Effective porosity, producible fluid and permeability in carbonates from NMR logging", SPWLA-1994-A, SPWLA 35th Annual 
Logging Symposium, Oklahoma, USA, (1994), June 19-22.

[12] Donaldson, E. C., Ewall, N., \& Singh, B., "Characteristics of capillary pressure curves," Journal of Petroleum Science and Engineering, (1991), 6 (3), 249-261.

[13] Forbes, P, "Simple and accurate methods for converting centrifuge data into drainage and imbibition capillary pressure curves," The Log Analyst, (1994), 35 (04), 35-53.

[14] Masalmeh, S. K, "Impact of capillary forces on remaining oil saturation and flooding experiments for mixed to oil-wet carbonate reservoirs", SCA2012-11, International Symposium of the Society of Core Analysts, Aberdeen, Scotland, UK, (2012), August 27-30. 